\title{
The availability of useful information to the right of fixation in reading
}

\author{
KEITH RAYNER, ARNOLD D. WELL, ALEXANDER POLLATSEK, \\ and JAMES H. BERTERA \\ University of Massachusetts, Amherst, Massachusetts
}

\begin{abstract}
A series of experiments that examined the characteristics of useful information to the right of fixation during reading is reported. In Experiments 1 and 2, reading performance when the information available to the right of fixation was determined by a fixed number of letters was compared with reading performance when the information to the right of fixation was determined by a fixed number of words. Beyond making more letters visible, both experiments showed that preserving all of the letters of a word was of no special benefit to reading. By explicitly presenting parts of the word to the right of fixation as well as the fixated word, Experiments 3 and 4 followed up on the implication that readers utilize partial letter information from words. Both experiments showed that reading was improved by this partial information and that preserving three letters of the word to the right of fixation improved reading almost as much as presenting the entire word. The implications the results have for models of reading are discussed.
\end{abstract}

A great deal of recent research (Den Buurman, Boersema, \& Gerrissen, 1981; Ikeda \& Saida, 1978; McConkie \& Rayner, 1975; Pollatsek, Bolozky, Well, \& Rayner, 1981; Rayner, 1975; Rayner \& Bertera, 1979; Rayner, Inhoff, Morrison, Slowiaczek, \& Bertera, 1981; Rayner, Well, \& Pollatsek, 1980) has focused on the characteristics of the perceptual span in reading (the region of the effective visual field during an eye fixation). This research has utilized techniques introduced by McConkie and Rayner (1975) and Rayner (1975) in which eye movements are recorded and display changes are made on a cathode-ray tube (CRT) from which the subject is reading that are contingent upon the subject's eye position. In general, the results of these experiments have indicated that for readers of English the perceptual span extends from the beginning of the currently fixated word (but no more than 3 or 4 characters to the left of fixation) to about 15 characters to the right of fixation. To the right of fixation, different types of information seem to be acquired. Information useful for identifying the meaning of a word is obtained within the foveal region and the beginning of the parafoveal region. There appears to be a region slightly farther to the right where some letter features are extracted and used, but which do not lead to word identification on that fixation. Word-length information useful in guiding eye movements to the next location (Pollatsek \& Rayner, in press; Rayner \& McConkie, 1976) is acquired even farther from fixa-

This research was supported by Grant HD12727 from the National Institute of Child Health and Human Development. Requests for reprints should be sent to Keith Rayner, Department of Psychology, University of Massachusetts, Amherst, Massachusetts 01003. tion (out to about 15 character spaces). For readers of Hebrew, for whom the direction of reading is from right to left, the perceptual span is asymmetric to the left (Pollatsek et al., 1981).

Although there has been considerable research on the perceptual span and many of the effects described above have been replicated in several experiments, there remain a number of unanswered questions about the characteristics of the perceptual span. Here, we will focus on the extent to which the perceptual span to the right of the fixation point is influenced by word integrity. That is, in all of the prior research using the technique developed by McConkie and Rayner (1975) in which a "window" moved with the eye across the text, the window controlled by the experimenter has been defined in terms of character spaces and the integrity of words has not been considered. In Experiments 1 and 2, we compared reading performance when the window area to the right of fixation consisted of (1) a fixed number of letters or (2) a fixed number of words. In the former condition, the number of words visible (i.e., physically present in the display) to the right of fixation varied from fixation to fixation and parts of words were often visible, whereas in the latter condition, the number of words visible to the right of fixation was constant but the number of letters varied from fixation to fixation. If, on the average, the same number of characters are visible in both conditions, the latter condition should produce better reading performance if integrity of words is important. If the integrity of words is not important, then there should be little difference.

In Experiments 3 and 4, we further examined the characteristics of the perceptual span by asking 
subjects to read text in which the amount of information visible to the right of the currently fixated word was systematically varied. In all conditions, the letters to the left of fixation as well as any remaining letters in the currently fixated word were presented unaltered. In one condition, all letters to the right of the currently fixated word were replaced by other letters. In another condition, the whole word to the right of the currently fixated word was also visible. In the most interesting conditions, partial information about the word to the right of the currently fixated word was presented. In both experiments, there were conditions in which three letters in the word to the right were visible, with the added constraint that the whole word was never fully visible (the details of this condition will be fully explained later). If reading performance is better in these conditions than when no letter information is available to the right of the fixated word, then this would be strong evidence that readers can use partial information from words. Previously, Rayner, McConkie, and Zola (1980) reported results from experiments dealing with the types of information subjects are able to obtain from a parafoveally presented word on fixation $n$ that facilitates the identification of that word on fixation $\mathrm{n}+1$. Their data, obtained from a task in which subjects named the word presented on fixation $n+1$, showed that preliminary identification occurs for letters of words presented in parafoveal vision. Their data also showed that the facilitation in the naming task resulted from activation of codes at a level more abstract than the specific visual characteristics of the letters, yet facilitation could occur when the parafoveal information integrated was insufficient for full identification of the word. (This integration occurred even though subjects could not identify the parafoveal stimulus.) In Experiments 3 and 4, we were interested in extending the finding that partial word information in the parafovea can facilitate word identification in a task in which subjects were reading rather than simply naming words as in the Rayner, McConkie, and Zola (1980) experiments.

In the experiments to be described, word-length information in all conditions was preserved by leaving the spaces between words intact. However, as in the original McConkie and Rayner (1975) experiment, we varied the characteristics of the pattern outside the window area by replacing the letters from the original text with Xs, with visually similar letters, or with dissimilar letters. By varying the pattern of text outside the window area, we hoped to be able to gain further information about the characteristics of different types of information acquired from different regions within the perceptual span.

\section{GENERAL METHOD}

\section{Subjects}

Members of the University of Massachusetts community were paid for their participation in the experiments. All of the subjects were recruited from a pool of subjects who were experienced in eye-movement experiments. All of the subjects had normal, uncorrected vision.

\section{Procedure}

When a subject arrived for an experiment, a bite bar that eliminated head movements during the experiment was prepared. Then the initial calibration of the eye-movement recording system took place. This initial calibration was accomplished in less than $5 \mathrm{~min}$. The subjects then read 16 individually presented sentences for warm-up. These warm-up sentences consisted of sample conditions from the particular experiment being run. Following the reading of the warm-up sentences, the subjects were instructed to read for understanding a number of sentences presented on the CRT. They were told that they would periodically be asked to release the bite bar and report (verbatim or paraphrased) the sentence they had just read. After reading each sentence, the subject pushed a button that resulted in the disappearance of the sentence from the CRT. The disappearance of the sentence was followed by the occurrence of three calibration targets. When the calibration targets appeared, a fourth cross that moved in perfect synchrony with the subject's eye was also present. The experimenter asked the subject to fixate the center calibration target. If one cross was superimposed on the other, the experimenter instructed the subject to move to the leftmost calibration target. When the subject had done so, the experimenter pushed a button that resulted in the presentation of the next sentence.

\section{Materials and Apparatus}

Sentences containing five to eight words were used as stimuli in the experiment. The sentences extended up to 42 characters per line and had a variety of syntactic structures. All of the sentences were easy to understand, and none contained ambiguities or subtle manipulations that would make them difficult to process.

The sentences were displayed on a Hewlett-Packard 1300A CRT, which has a P-31 phosphor with the characteristic that removing a character results in a drop to $1 \%$ of maximum brightness in $.25 \mathrm{msec}$. The letters making up the sentences were printed in lowercase (except for the first letter of the sentence) on the CRT. A black theater gel covered the CRT so that the letters appeared clear and sharp to the subjects.

Eye-movement recording was accomplished by using a Stanford Research Institute Dual Purkinje eyetracker, which has a resolution of $10 \mathrm{~min}$ of arc and a linear output over the visual angle (14 deg) that was occupied by the sentences. The eyetracker and the CRT were interfaced to a Hewlett-Packard 2100 computer that controlled the experiment. The signal from the eyetracker was sampled every $1 \mathrm{msec}$, and the position of the eye was determined every $4 \mathrm{msec}$. The display changes associated with each eye movement were accomplished within $5 \mathrm{msec}$ of the completion of the saccade." The computer kept a complete record of the duration, sequence, and location of each fixation.

In the experiments, the subject's eye was $46 \mathrm{~cm}$ from the CRT and three characters equaled $1 \mathrm{deg}$ of visual angle. Eye movements were monitored from the right eye, although viewing was binocular. Luminance on the CRT was adjusted to a comfortable level for the subjects, and the subjective brightness was held constant throughout the experiment. The room was dark, except for a dim indirect light source. More details about the characteristics of the apparatus are described by Rayner et al. (1981).

\section{EXPERIMENT 1}

One question that has remained unanswered in prior research on the perceptual span concerns the extent to which the effective visual field corresponds to word boundaries. As mentioned previously, in prior research the window has always been defined in terms of character spaces. It may well be the case, however, that the perceptual span of the subject is 
best defined in terms of words rather than of character spaces. One would expect that, if the perceptual span was defined in terms of words, reading should proceed more smoothly when the "presentation window" was also defined in terms of words. Thus, it is quite possible that there will be less disruption of reading because of the restrictions of information on some fixations with a small window if word integrity is preserved (i.e., there are no words that lie only partly within the window) than there will be on fixations, with the same-sized window, in which word integrity is not preserved. On the other hand, if the pickup of visual information remains fairly constant in terms of character spaces and if it is not particularly important to see words in their entirety on a fixation, then we should not expect any differences between a window determined by words and one determined by character positions, as long as the windows are equated in terms of average number of characters visible in the window. In Experiment 1, the subjects read sentences presented on the CRT under conditions in which (1) only the currently fixated word was visible to the right of the fixation, (2) the currently fixated word and one word to the right were visible, (3) the currently fixated word and two words to the right were visible, and (4) the currently fixated word and three words to the right were visible. In conditions determined by character positions, (1) 3 characters to the right of fixation were visible, (2) 9 letters to the right of fixation were visible, (3) 15 letters to the right of fixation were visible, or (4) 21 letters to the right of fixation were visible. In addition, there was a control condition in which the whole line was visible. The sizes of the windows defined by character positions were determined by estimating the average number of letters that would be visible to the right of fixation under the conditions in which the window was determined by the word boundaries. For example, when the subject had only the word currently fixated and the word to the right of fixation available, we estimated that, on the average, nine characters would be available to the right of fixation. In fact, these estimates were fairly good and the conditions were quite comparable (see Table 1). Reading performance (in terms of a number of measures) was compared between the word windows and the letter windows.

\section{Method}

There were nine conditions in the experiment. In four of the conditions, the window corresponded to word boundaries (word windows). These conditions will be referred to as $0 \mathrm{~W}, 1 \mathrm{~W}, 2 \mathrm{~W}$, and $3 \mathrm{~W}$. The numeral refers to the number of words to the right of the currently fixated word that were visible: $0 \mathrm{~W}$ means that only the currently fixated word was visible, $1 \mathrm{~W}$ means that the currently fixated word and the word to the right of fixation were both visible, and so on. In four other conditions, the window corresponded to letter spaces (letter windows). These conditions will be referred to as $3 \mathrm{~L}, 9 \mathrm{~L}, 15 \mathrm{~L}$, and $21 \mathrm{~L}$. The numeral refers to the number of letters to the right of the fixation point that were visible, with the spaces between words counting as letters. In the word windows and the letter windows, the spacing between words was preserved and every letter to the right of the specified window area for a particular window size was replaced with an $X$. In all of the conditions, all of the text to the left of the fixation point was presented normally, so that there was a limit only on the amount of information available to the right of the fixation point. In addition to the eight experimental conditions that have been described, there was also a control condition in which the entire line of text was presented normally.

Nine subjects participated in the experiment, and the conditions were counterbalanced across the subjects. After having read the warm-up sentences, each subject read eight sentences in each of the nine conditions. The eight sentences for each condition were presented in a block, and the nine blocks were presented in the same order to each subject, with conditions counterbalanced across the blocks.

\section{Results and Discussion}

The number and mean length of forward and regressive saccades were computed for each subject, as were the mean durations of fixations following forward and regressive eye movements. Reading rate was defined as the number of words presented divided by the time from when the line of text was initially presented until the button was pressed indicating that the sentence had been read. Table 1 displays the results for

Table 1

Means for the Dependent Variables in Experiment 1

\begin{tabular}{|c|c|c|c|c|c|}
\hline $\begin{array}{l}\text { Window } \\
\text { Condition }\end{array}$ & $\begin{array}{l}\text { Total } \\
\text { Fixations }\end{array}$ & $\begin{array}{l}\text { Forward } \\
\text { Fixations }\end{array}$ & $\begin{array}{c}\text { Forward Fixation } \\
\text { Duration }\end{array}$ & $\begin{array}{c}\text { Forward Saccade } \\
\text { Length }\end{array}$ & $\begin{array}{c}\text { Reading } \\
\text { Rate }\end{array}$ \\
\hline No Mask & 5.1 & 4.5 & 218 & 7.2 & 348 \\
\hline ow $\quad(3.7)$ & 6.5 & 6.0 & 271 & 5.7 & 212 \\
\hline $1 \mathrm{~W}$ & 5.3 & 5.1 & 226 & 6.5 & 309 \\
\hline $2 \mathrm{~W}(15.0)$ & 5.0 & 4.9 & 220 & 6.8 & 339 \\
\hline $3 W(20.8)$ & 5.0 & 4.6 & 221 & 6.9 & 339 \\
\hline $3 \mathrm{~L}$ & 7.3 & 6.8 & 252 & 5.4 & 207 \\
\hline $9 \mathrm{~L}$ & 5.6 & 5.2 & 221 & 6.5 & 308 \\
\hline $15 \mathrm{~L}$ & 5.1 & 4.8 & 216 & 6.9 & 340 \\
\hline $21 \mathrm{~L}$ & 5.0 & 4.6 & 220 & 7.3 & 342 \\
\hline$\Gamma(8,64)^{*}$ & 25.44 & 19.32 & 13.61 & 11.05 & 20.88 \\
\hline
\end{tabular}

Note-Mean forward fixation duration is given in milliseconds and refers to fixation durations following a forward saccade. Forward saccade length is given in characters. Reading rate is given in words per minute. Values in parentheses correspond to the average number of letters visible in the $W$ condition. ${ }^{*} p<.001$ in all cases. 
reading rate, forward fixations, and the total number of fixations. Information about regressive eye movements is not displayed because the mean number of regressions per sentence did not exceed .6 in any condition. Consequently, discussion of subsequent analyses will be confined only to the dependent variables shown in Table 1, especially reading rate, which we have found in a number of studies to be the most sensitive and meaningful dependent variable. It should be noted, however, that reading rate does include regressions and that the total number of fixations includes forward and regressive eye movements.

All of the dependent variables were influenced by window size (all Fs $>11.1$, ps $<.001$ ). The major focus of this study was, however, to determine whether reading performance in the word conditions would be different from performance in the corresponding letter conditions. Since a repeated measures design was employed, pairwise comparisons were performed using the Bonferroni $t$ test, as recommended by Myers (1979). The nine conditions of Experiment 1 provided 36 pairwise comparisons, and so the error rate per comparison was set at .001 .

Reading rate. Although, in every case, reading rate increased with window size, reaching asymptote by the $2 \mathrm{~W}$ and $15 \mathrm{~L}$ conditions, there was absolutely no tendency for any of the word conditions to differ from the corresponding letter conditions. That is, $0 \mathrm{~W}$ did not differ from $3 \mathrm{~L}, 1 \mathrm{~W}$ did not differ from $9 \mathrm{~L}, 2 \mathrm{~W}$ did not differ from $15 \mathrm{~L}$, and $3 \mathrm{~W}$ did not differ from $21 \mathrm{~L}$ [all ts $(8)<1$, ps $>.5$ ]. Reading rate was significantly lower for the $0 \mathrm{~W}$ and $3 \mathrm{~L}$ conditions than for any of the others (all ts $>5.0, p<.001$ ), and there was a consistent tendency for reading rate to be lower for the $1 \mathrm{~W}$ and $9 \mathrm{~L}$ conditions than for any of the four larger window conditions and the control (all ts $>2.1$, ps $<.068$ ).

Although the mean number of characters visible was closely matched in the word conditions and the corresponding letter conditions, several more detailed analyses were performed to determine whether windows would be better defined in terms of words or in terms of characters (cf. Rayner, Well, \& Pollatsek, 1980). The first analysis was based on the fact that, if word boundaries are irrelevant, it should be possible to predict reading rates in the word conditions as weighted averages of reading rates in letter conditions. Since such predictions average rates over conditions, the appropriate average is given by the harmonic mean $1 / \Sigma p_{i} t_{i}$ where $p_{i}$ is the proportion of fixations that $i$ characters were available to the right of fixation in the word condition and $t_{i}$ is the estimated mean reading time per word (the reciprocal of reading rate) for a window in which $i$ characters are visible to the right of fixation. For $i=3,9,15$, and 21 , $t_{i}$ was directly available from the letter conditions, and for other values of $i$, it was estimated by using a smooth exponential curve fit to the data of the letter conditions. Because the last "character" in each word condition was always a space, there was ambiguity in the definition of how many characters were visible to the right of fixation on a given fixation. Consequently, two separate analyses were performed, one counting the final space as a character in the window and the other not counting the space. If the space was counted as a character, predicted reading rates for the $0 \mathrm{~W}$ and $1 \mathrm{~W}$ conditions were 206 and 304 words per minute (wpm), respectively, almost identical to the observed values of 207 and 308 . If the final spaces were not counted, the predictions were 181 and $292 \mathrm{wpm}$, respectively. Predictions were not made for the $2 \mathrm{~W}$ and $3 \mathrm{~W}$ conditions, since windows would almost always consist of at least nine characters to the right of fixation in these conditions and hence, since performance approached asymptotic levels, prediction could not differ by much from the observed values. In sum, this analysis provides little evidence to suggest that windows are better defined in terms of words than in terms of characters to the right of fixation. Since the predictions for the word conditions from the letter conditions are a bit lower than the observed values if the space at the end of the word is not counted as a character, there is a suggestion that word integrity may help to define the perceptual span. However, this evidence is weak since this seems like a "worst case" analysis as the space conveys some information and should count for something. Furthermore, in the letter conditions, the last character of the window was sometimes a space.

The converse analysis, on the other hand, seems less problematical, since it requires no curve fitting or arbitrary assumptions. If word integrity is crucial for defining the window, reading rate in a given condition should be determined by the number of words seen in their entirety. Under this assumption, reading rate in a given letter condition should be predictable from the rates in word conditions. The second analysis, then, compared reading rate in the $9 \mathrm{~L}$ condition with that predicted from the word conditions, assuming windows were effectively defined by the number of words displayed in their entirety. This analysis was performed only for the $9 \mathrm{~L}$ condition. (It was not performed for the $15 \mathrm{~L}$ and $21 \mathrm{~L}$ conditions because, since performance there approaches asymptote, the analysis would be insensitive, and it was not performed for the $3 \mathrm{~L}$ condition because that condition would require that one know the reading rate in a hypothetical condition when the currently fixated word was never fully visible.) For the 9L condition, the currently fixated word was not entirely visible on less than $1 \%$ of the fixations, the currently fixated word, but no other word to the right of it, was entirely visible on $46 \%$ of the fixations, one word to the right of the currently fixated word was entirely 
visible on $48 \%$ of the fixations, and a second word to the right was entirely available on $6 \%$ of the fixations.

The prediction was made for each subject separately so that the reliability of the difference between the predicted and observed rates could be assessed. The average reading rate predicted in the $9 \mathrm{~L}$ condition was $252 \mathrm{wpm}$, which was significantly lower than the observed rate of $304 \mathrm{wpm}[\mathrm{t}(8)=4.3, \mathrm{p}<.01]$. Thus, it is clear that performance in the $9 \mathrm{~L}$ condition was far better than could be predicted from the number of words that were visible in their entirety. While no precise analysis could be done for the $3 \mathrm{~L}$ condition, the same conclusion seems to follow. In this condition, a word to the right of the currently fixated word was entirely visible on only $2 \%$ of the fixations, only the currently fixated word and words to the left were entirely visible on $63 \%$ of the fixations, and the currently fixated word was not entirely visible on $35 \%$ of the fixations. If word integrity is important, it seems clear that performance in the $3 \mathrm{~L}$ condition should be much worse than in the $0 \mathrm{~W}$ (currently fixated word visible) condition, since on $35 \%$ of the fixations the currently fixated word was not entirely visible and on only $2 \%$ of the fixations was an additional whole word visible to the right. In fact, performance in the $3 \mathrm{~L}$ and $0 \mathrm{~W}$ conditions was almost identical.

Thus, the reading-rate data of Experiment 1 are quite consistent with a model that states that the window to the right of fixation is determined by the number of characters visible. Our data indicate that the effective visual field for character information extends at least nine characters to the right of fixation [the reading rate tended to be somewhat greater in the 15L condition than in the $9 \mathrm{~L}$ condition; $t(8)=$ $2.7, p=.026]$. Data from the word conditions suggest that character information from the second word to the right is sometimes extracted. The overall finding that the right boundary of the window seems to be defined in terms of number of characters visible is in marked contrast with our finding (Rayner, Well, \& Pollatsek, 1980) that the left boundary of the window is primarily determined by the beginning of the currently fixated word. Although our data show that reading rate is predicted by the number of letters of normal text displayed to the right of fixation, it is possible that the window of text actually processed at any given moment may be defined by a more complex rule. The size of the window may vary from fixation to fixation, and it may be determined by other factors as well, such as number of morphemes, syllables, or the like. The major claim we would like to make is that the window to the right is not solely defined by the number of words displayed. Although our data do not rule out other models, the number of letters visible to the right of fixation appears to be a simple and viable model.
Other dependent variables. As was found for the reading-rate data, there was no significant tendency for any of the other dependent variables for the word conditions to differ from the corresponding letter conditions. The only such differences that even approached significance resulted from the tendency for there to be more forward fixations $[t(8)=2.92, p=$ $.091]$ and total fixations $[t(8)=2.85, p=.021]$ in the $3 \mathrm{~L}$ condition than in the $\mathrm{OW}$ condition. For no other difference was $\mathrm{p}<.089$.

There were a number of significant pairwise differences for each of the other dependent variables. All differences significant at the $\mathrm{p}<.001$ level were due to the two smallest window conditions (OW and $3 \mathrm{~L}$ ) differing from the larger window conditions. Fixation durations were longer for the $\mathrm{OW}$ and $3 \mathrm{~L}$ conditions than for the other seven conditions, for which the means were bunched between 216 and $226 \mathrm{msec}$. The $0 \mathrm{~W}$ condition differed from the $2 \mathrm{~W}, 3 \mathrm{~W}, 9 \mathrm{~L}$, $15 \mathrm{~L}, 21 \mathrm{~L}$, and no-mask conditions (all ps $<.001$ ) and from the $1 \mathrm{~W}$ condition $(\mathrm{p}<.007)$. The $3 \mathrm{~L}$ condition differed from the $3 \mathrm{~W}, 9 \mathrm{~L}, 15 \mathrm{~L}$, and $21 \mathrm{~L}$ conditions $(p<.001)$ as well as the $1 W(p=.015), 2 W(p=.004)$, and no-mask $(p=.003)$ conditions. No other differences approached significance.

Saccade lengths were shorter in the $0 \mathrm{~W}$ condition than in the $3 \mathrm{~W}, 15 \mathrm{~L}, 21 \mathrm{~L}$, and no-mask conditions $(p<.001)$ and the $1 \mathrm{~W}(\mathrm{p}=.003), 2 \mathrm{~W}(\mathrm{p}=.011)$, and 9L $(p=.016)$ conditions. A similar pattern of results was found for the differences in saccade length between the $3 \mathrm{~L}$ conditions and the larger window conditions (all ps $<.003$ ).

Since the pattern of significant results was almost identical for forward fixations and total fixations, only the former will be discussed. There were more forward fixations in the $\mathrm{OW}$ condition than in the $1 \mathrm{~W}, 2 \mathrm{~W}, 3 \mathrm{~W}, 15 \mathrm{~L}, 21 \mathrm{~L}$, and no-mask conditions $(p<.001)$ and in the $9 \mathrm{~L}$ condition $(p=.023)$. A similar pattern of results was found for the differences between the $3 \mathrm{~L}$ condition and the larger window conditions (all ps $<.003$ ). In addition, as mentioned earlier, there tended to be more fixations in the $3 \mathrm{~L}$ condition than in the $\mathrm{OW}$ condition. It would not be too surprising to find a difference in the number of fixations here, since in the $3 \mathrm{~L}$ condition the currently fixated word was not entirely visible on $35 \%$ of the fixations. Subjects may have needed to make more fixations to check the ends of longer words in the $3 \mathrm{~L}$ condition than they did in the $0 \mathrm{~W}$ condition, in which all of the currently fixated word was visible. If they did do so, however, it did not seem to diminish their reading rate, which was almost the same in the $3 \mathrm{~L}$ condition (207 wpm) as in the OW condition (212 wpm). Any effect on reading rate due to additional fixations may have been balanced out by the tendency for there to be somewhat shorter fixation durations in the $3 \mathrm{~L}$ than in the $0 \mathrm{~W}$ condition. This effect was, however, not significant $(p=.098)$. The only other 
differences to approach significance were due to the tendency for there to be more fixations in the $1 \mathrm{~W}$ condition than in the $3 \mathrm{~W}(\mathrm{p}=.006)$ and no-mask $(p=.002)$ conditions, and for there to be more fixations in the $9 \mathrm{~L}$ condition than in the $3 \mathrm{~W}(\mathrm{p}=.028)$ and no-mask $(p=.015)$ conditions.

\section{EXPERIMENT 2}

In Experiment 1, we found no evidence that the effective visual field to the right of fixation was correlated with no word boundaries. The results indicated that reading performance in the condition in which the window was defined in terms of number of words was very similar to that in the condition in which the window was defined in terms of number of letters (and in which word integrity was not necessarily preserved). Also, as window size increased, reading performance improved. (The latter result has been found in many previous studies.) The general implication to be drawn from Experiment 1 is that as long as readers have clear information about a certain number of letters to the right of fixation and have word spacing information, it does not matter if the window corresponds to word boundaries. In part, this result suggests that letter information in parafoveal vision is useful even when that information does not directly lead to word identification on the current fixation. We shall address this issue more directly in Experiments 3 and 4.

In Experiment 2, we replicated Experiment 1 and, in addition, varied the characteristics of the information outside the window area. In many ways, it is surprising that with the smallest windows used in Experiment 1 there were no differences between the word and letter windows. It would seem that when the window is small ( $0 \mathrm{~W}$ and $3 \mathrm{~L}$ conditions), reading should proceed more smoothly if the entire word currently fixated is available than if it is perturbated. Yet, in a number of analyses, we found no indication that this was the case. Hence, we replicated part of Experiment 1 by replacing letters outside the window area with Xs, similar letters, or dissimilar letters. Previously, McConkie and Rayner (1975) had found that reading performance was best when the pattern outside the window area consisted of Xs, next best when it consisted of visually similar letters, and poorest when dissimilar letters were outside the window.

The other major difference between Experiment 1 and Experiment 2 was that we restricted the window to the left of fixation in Experiment 2. In prior research, we (Rayner, Well, \& Pollatsek, 1980) had found that the area of effective vision to the left of fixation extends to the beginning of the currently fixated word, but no more than three or four letters to the left of fixation. Hence, to be more precise about the window, the left-hand boundary was con- trolled as well: the window extended to the beginning of the currently fixated word. As in Experiment 1, spaces between words were preserved to the left and right of fixation. Four window sizes were utilized in Experiment 2: $0 \mathrm{~W}, 1 \mathrm{~W}, 3 \mathrm{~L}$, and $9 \mathrm{~L}$.

\section{Method}

There were 12 conditions in the experiment corresponding to a 4 (window size) $\times 3$ (parafoveal text pattern) design. The four window sizes utilized in the experiment were $0 \mathrm{~W}, 1 \mathrm{~W}, 3 \mathrm{~L}$, and $9 \mathrm{~L}$. These four conditions were identical to those used in Experiment 1 except that the left boundary of the window extended only to the beginning of the currently fixated word. As in Experiment 1, all spaces outside the window were preserved. One of the parafoveal text patterns was identical to that used in Experiment 1; in this pattern, every letter was replaced by an $X$ ( $X$ condition). In the similar (S) condition, every letter outside the window region was replaced by its most visually similar letter. The letter substitutions were based on a confusability matrix generated by Bouma (1973). Every ascender was replaced by an ascender, every descender was replaced by a descender, and letters that did not extend above or below the line of print were replaced by other similar nonascending or nondescending letters. In the dissimilar (D) condition, every letter was replaced by a dissimilar letter, with ascenders replaced by descenders or letters that did not extend above or below the line, and so on.

Six subjects participated in the experiment. After reading 8 warm-up sentences, each subject read 8 sentences in each of the 12 conditions, with the 8 sentences in each condition presented in a block. All subjects read the 96 experimental sentences in the same order, and the order of the 12 conditions was randomized separately for each of the six subjects.

\section{Results and Discussion}

The results of Experiment 2 are displayed in Table 2 . The major analyses performed were 4 (window size) $\times 3$ (parafoveal text pattern) analyses of variance and pairwise contrasts.

Reading performance was strikingly poorer in Experiment 2 than in Experiment 1. In the conditions of Experiment 2 most comparable to those in Experiment 1 (parafoveal text pattern consisting of $\mathrm{Xs}$ ), reading rate averaged $65 \mathrm{wpm}$ less and, in addition, there were sizable changes (more forward fixations and regressions, longer fixation durations, and shorter saccade lengths) in the other dependent variables. In previous work (Rayner, Well, \& Pollatsek, 1980 ), we had found that when normal text was presented to the right of fixation, the effective visual field did not extend farther to the left than the beginning of the currently fixated word. From the results of the present experiment, however, it seems quite clear that information to the left of the currently fixated word is used when information to the right is restricted. We shall return to this point later.

Changing window size influenced all of the dependent variables, as in Experiment 1 [all $\mathrm{Fs}(3,15)>$ 11.28 , ps $<.001$ ]. In addition, the effect of the parafoveal text pattern was significant for reading rate $[F(2,10)=7.88, p<.01]$. Reading was fastest when the parafoveal text pattern consisted of Xs and was slowest when it consisted of dissimilar letters. This difference was significant $[t(5)=3.82, p<.025]$. 
Table 2

Means for Dependent Variables in Experiment 2

\begin{tabular}{|c|c|c|c|c|c|c|}
\hline $\begin{array}{l}\text { Parafoveal Text } \\
\text { Pattern }\end{array}$ & $\begin{array}{l}\text { Window } \\
\text { Condition }\end{array}$ & $\begin{array}{c}\text { Total } \\
\text { Fixations }\end{array}$ & $\begin{array}{l}\text { Forward } \\
\text { Fixations }\end{array}$ & $\begin{array}{l}\text { Forward Fixa- } \\
\text { tion Durations }\end{array}$ & $\begin{array}{l}\text { Forward Sac- } \\
\text { cade Length }\end{array}$ & $\begin{array}{c}\text { Reading } \\
\text { Rate }\end{array}$ \\
\hline Xs & $\begin{array}{l}0 \mathrm{~W} \\
1 \mathrm{~W} \\
3 \mathrm{~L} \\
9 \mathrm{~L}\end{array}$ & $\begin{array}{l}8.2 \\
6.5 \\
8.6 \\
7.0\end{array}$ & $\begin{array}{l}7.4 \\
6.2 \\
7.7 \\
6.6\end{array}$ & $\begin{array}{l}283 \\
233 \\
280 \\
246\end{array}$ & $\begin{array}{l}5.0 \\
5.4 \\
4.9 \\
5.2\end{array}$ & $\begin{array}{l}158 \\
247 \\
153 \\
217\end{array}$ \\
\hline $\begin{array}{l}\text { Similar } \\
\text { Letters }\end{array}$ & $\begin{array}{l}0 W \\
1 W \\
3 L \\
9 L\end{array}$ & $\begin{array}{l}8.8 \\
7.7 \\
9.2 \\
7.8\end{array}$ & $\begin{array}{l}7.6 \\
6.7 \\
7.7 \\
6.6\end{array}$ & $\begin{array}{l}276 \\
257 \\
277 \\
257\end{array}$ & $\begin{array}{l}5.0 \\
5.6 \\
5.1 \\
5.7\end{array}$ & $\begin{array}{l}153 \\
200 \\
142 \\
192\end{array}$ \\
\hline $\begin{array}{l}\text { Dissimilar } \\
\text { Letters }\end{array}$ & $\begin{array}{l}0 \mathrm{~W} \\
1 \mathrm{~W} \\
3 \mathrm{~L} \\
9 \mathrm{~L}\end{array}$ & $\begin{array}{r}9.9 \\
8.3 \\
10.5 \\
8.6\end{array}$ & $\begin{array}{l}8.0 \\
6.8 \\
8.8 \\
7.1\end{array}$ & $\begin{array}{l}289 \\
267 \\
286 \\
259\end{array}$ & $\begin{array}{l}5.1 \\
5.7 \\
4.6 \\
5.5\end{array}$ & $\begin{array}{l}129 \\
164 \\
124 \\
171\end{array}$ \\
\hline $\begin{array}{l}\text { Average } \\
\text { Over } \\
\text { Patterns }\end{array}$ & $\begin{array}{l}0 W \\
1 W \\
3 \mathrm{~L} \\
9 \mathrm{~L}\end{array}$ & $\begin{array}{l}9.1 \\
7.5 \\
9.3 \\
7.8\end{array}$ & $\begin{array}{l}7.7 \\
6.6 \\
8.0 \\
6.8\end{array}$ & $\begin{array}{l}283 \\
252 \\
281 \\
254\end{array}$ & $\begin{array}{l}5.0 \\
5.6 \\
4.9 \\
5.5\end{array}$ & $\begin{array}{l}146 \\
204 \\
140 \\
193\end{array}$ \\
\hline
\end{tabular}

There were also parafoveal text pattern main effects for forward fixations $[F(2,10)=4.26, p<.05]$ and regressions $[F(2,10)=10.8, p<.001]$. In particular, there were fewer regressions when the parafoveal text pattern consisted of $\mathrm{Xs}$ than when it consisted of similar and dissimilar letters $[\mathrm{t}(5)=3.80, \mathrm{p}<.025]$. There were no interactions between parafoveal text pattern and window size for any dependent variable.

As in Experiment 1, the major focus of the experiment was to investigate whether reading performance in the word conditions was different from that in the corresponding letter conditions. Although the data were more variable than in Experiment 1, the word and corresponding letter conditions were again very similar. Averaged over parafoveal text pattern, reading rate was significantly greater for the $9 \mathrm{~L}$ and $1 \mathrm{~W}$ conditions than for the $3 \mathrm{~L}$ and $0 \mathrm{~W}$ conditions $[\mathrm{t}(5)=4.14, \mathrm{p}<.01]$. There was, however, no tendency for the $0 \mathrm{~W}$ reading rate to differ from the $3 \mathrm{~L}$ rate $[t(5)=1.03, p=.352]$ or for the $1 \mathrm{~W}$ rate to differ from the $9 \mathrm{~L}$ rate $[\mathrm{t}(5)=.75, \mathrm{p}=$ .489]. There was a 30-wpm difference in reading rate between the $1 \mathrm{~W}$ and $9 \mathrm{~L}$ conditions when the parafoveal text consisted of Xs $[\mathrm{t}(5)=2.85, \mathrm{p}=.036]$. However, this difference did not exceed 8 wpm in either the dissimilar or similar letters condition $(p>$ .7), and, in fact, was in the opposite direction for dissimilar letters. There was no tendency for the $0 W$ reading rates to differ from the $3 \mathrm{~L}$ rates in any parafoveal text pattern condition (all ps $>$.6).

When averaged over the different parafoveal text conditions, the data for the other dependent variables were remarkably similar for the word and corresponding letter conditions. The $0 \mathrm{~W}$ and $3 \mathrm{~L}$ conditions differed by $2 \mathrm{msec}$ in mean forward fixation duration, by .1 characters in mean forward saccade length, and by .3 forward fixations and .1 regres- sions per sentence. The corresponding differences for the $1 \mathrm{~W}$ and $9 \mathrm{~L}$ conditions were $2 \mathrm{msec}, .1$ characters, .2 forward fixations, and .1 regressions. Even when the different parafoveal text conditions were analyzed separately, none of the 24 pairwise comparisons approached significance (all ps $>.10$ ). Consequently, our conclusion from Experiment 1 that the effective visual field to the right of fixation is defined in terms of the number of characters visible is also supported by Experiment 2 .

We found the differences in reading performance between comparable conditions in Experiments 1 and 2 quite surprising, since our previous research (Rayner, Well, \& Pollatsek, 1980) had established that when the subject was presented with normal text to the right of fixation, reading was virtually unaffected by the presence or absence of information to the left of the currently fixated word. However, the markedly different reading rates in Experiments 1 and 2 imply that information to the left of the fixated word is being utilized when information to the right of fixation is disturbed.

To try to get a more precise picture of the use of information to the left of fixation, the patterns of the subjects' fixations were analyzed. Of primary interest were how much information in Experiment 1 was processed by subjects when it was available only to the left of the fixated word and whether subjects frequently regressed to such information. While both the $0 \mathrm{~W}$ and $3 \mathrm{~L}$ conditions were analyzed, this discussion will focus on the $\mathrm{OW}$ conditions, since the chunks of text missed were whole words and are thus easier to analyze. As might be expected, since the window was smaller in Experiment 2 than in Experiment 1, fewer words were skipped in the latter. An average of .8 words/sentence were "skipped" (i.e., were never available to the right of fixation) 
in Experiment 2 on forward fixations (in this analysis, the term "forward fixations" refers to fixations for which there had not been any previous fixation farther to the right). In contrast, there were 1.88 words/sentence "skipped" in Experiment 1. Moreover, in Experiment 2, about $45 \%$ of the words that were "skipped" on forward fixations were later fixated by a regression, whereas in Experiment 1, only about $4 \%$ of the words "skipped" were later fixated; this difference is highly reliable across subjects $[\mathrm{t}(13)=$ $5.69, \mathrm{p}<.001]$. Thus, it appears that whole words to the left of fixation were processed in Experiment 1 , since the number of words never fixated in Experiment 2 (.44 per line) would be an estimate of the number of words that can be filled in from context and word length alone.

\section{EXPERIMENT 3}

In each of our first two experiments we found no evidence that preserving the integrity of words by having the window correspond to word boundaries facilitated reading over the condition in which the window was defined only in terms of number of letters. As suggested above, one implication of our finding is that letter information extracted from words not fully identified is useful in reading. Hence, there is the strong possibility that specific letter information from words not yet fixated is obtained on fixation $n$ and is used to facilitate word identification on fixation $n+1$ when the word that had been in parafoveal vision on fixation $n$ is fixated. In Experiment 3 , we directly tested this idea by varying the amount of information available about the word to the right of the currently fixated word. In one condition, the entire word to the right of the currently fixated word was available within each fixation. In three other conditions, partial information was available from the word to the right of the fixated word. The first letter, the first two letters, or the first three letters of that word were available with the constraint that the word was never fully visible. In prior research, Rayner, McConkie, and Zola (1980) had found that information about the first three letters of a parafoveally presented word on fixation $n$ facilitated naming of the word on fixation $n+1$ following an eye movement to the location of the parafoveally presented word. In Experiment 3, we tested the extent to which information about the beginning letters of words in parafoveal vision influences reading.

\section{Method}

There were 10 conditions in the experiment corresponding to a 5 (window size) $\times 2$ (parafoveal text pattern) design. In two of the conditions, the window size corresponded to word boundaries; these conditions were identical to the $0 \mathrm{~W}$ and $1 \mathrm{~W}$ conditions in the first two experiments. In the partial word condi- tions, the currently fixated (as well as all words to the left of fixation) word was always available and the first $(0 \mathrm{~W}+1 \mathrm{~L})$, the first two $(0 W+2 L)$, or the first three $(0 W+3 L)$ letters of the word to the right of the currently fixated word were available. We did not, however, display the whole next word in the $0 W+1 L$, $0 W+2 L$, and $0 W+3 L$ conditions, even when that word was short. In the case in which the word to the right of fixation was equal to or shorter than the number of letters to be exposed, we uniformly reduced by one the number of letters available unaltered in the short word. That is, the subject saw the number of letters in the window condition or the number of letters in the word minus one, whichever was less. Thus, for example, if the word to the right of fixation was a three-letter word and the subject was in the $0 \mathrm{~W}+2 \mathrm{~L}$ condition, the first two letters of the word were available and the other letter was replaced. If, however, the subject was in the $0 \mathrm{~W}+3 \mathrm{~L}$ condition, again only the first two letters of the three-letter words were made available (since we displayed the whole next word only in the $1 \mathrm{~W}$ condition). If the subject was in the $0 W+3 L$ condition and the word to the right of fixation was a four-letter word, the first three letters of the word were available and the fourth letter was replaced.

Two types of parafoveal text patterns were used outside the window area. These corresponded to the $S$ and $D$ conditions from Experiment 2, with all letters outside the window area replaced by visually similar letters in the $S$ condition and by dissimilar letters in the $\mathrm{D}$ condition: letter substitutions were made on the same basis as in Experiment 2. As in Experiments 1 and 2 , all spaces between words were preserved outside the window, and all information to the left of fixation was preserved (as in Experiment 1).

Ten subjects participated in the experiment, and the conditions were counterbalanced across the subjects. Following the reading of the 8 warm-up sentences, each subject read 8 sentences in each of the 10 conditions. The 80 experimental sentences were presented in the same order to each subject, with conditions counterbalanced across the blocks.

\section{Results and Discussion}

The results for Experiment 3 are displayed in Table 3. The major analyses performed were 5 (window size) $\times 2$ (parafoveal text pattern) analyses of variance and pairwise Bonferroni $t$ tests. Newman-Keuls tests were also performed, and the pattern of significant results agreed almost completely with that provided by the $t$ tests. Since the five levels of window size resulted in 10 pairwise comparisons, a significance level of .005 was chosen for the Bonferroni t.

Reading rate. The analysis of variance revealed highly significant main effects for window size $[F(4,36)=31.50, p<.001]$ and for parafoveal text pattern $[F(1,9)=20.02, p<.005]$, and a significant interaction between the two factors $[F(4,36)=2.97$, $\mathrm{p}<.05]$. Reading rate increased with increasing window size and was, on the average, higher when visually similar letters were displayed to the right of the window than when dissimilar letters were presented. This effect of similarity was particularly strong in the $0 \mathrm{~W}+1 \mathrm{~L}, 0 \mathrm{~W}+2 \mathrm{~L}$, and $0 \mathrm{~W}+3 \mathrm{~L}$ conditions (all ps $<.005$ ) and was much less so for the $0 W$ and $1 W$ conditions $(p=.16$ and $p=.20$, respectively), resulting in the interaction. This suggests that subjects are able to use information about the beginning letters of words in parafoveal vision to fa- 
Table 3

Means for the Dependent Variables in Experiment 3

\begin{tabular}{|c|c|c|c|c|c|}
\hline $\begin{array}{l}\text { Window } \\
\text { Condition }\end{array}$ & $\begin{array}{c}\text { Total } \\
\text { Fixations }\end{array}$ & $\begin{array}{l}\text { Forward } \\
\text { Fixations }\end{array}$ & $\begin{array}{c}\text { Forward Fixation } \\
\text { Duration }\end{array}$ & $\begin{array}{c}\text { Forward Saccade } \\
\text { Length }\end{array}$ & $\begin{array}{c}\text { Reading } \\
\text { Rate }\end{array}$ \\
\hline \multicolumn{6}{|c|}{ Similar Letters Conditions } \\
\hline $0 \mathrm{~W}$ & 6.1 & 5.5 & 243 & 6.6 & 251 \\
\hline $0 W+1 L$ & 5.6 & 5.2 & 232 & 6.8 & 281 \\
\hline $0 W+2 L$ & 5.6 & 5.2 & 234 & 6.7 & 286 \\
\hline $0 W+3 L$ & 5.4 & 5.1 & 232 & 6.9 & 301 \\
\hline $1 \mathrm{~W}$ & 5.2 & 4.9 & 219 & 7.0 & 329 \\
\hline \multicolumn{6}{|c|}{ Dissimilar Letters Conditions } \\
\hline ow & 6.3 & 5.7 & 248 & 6.1 & 234 \\
\hline $0 W+1 L$ & 6.4 & 5.8 & 249 & 6.1 & 232 \\
\hline $0 W+2 L$ & 6.1 & 5.6 & 251 & 6.4 & 242 \\
\hline $0 W+3 L$ & 5.9 & 5.4 & 242 & 6.4 & 265 \\
\hline $1 \mathrm{~W}$ & 5.2 & 4.9 & 226 & 7.0 & 312 \\
\hline
\end{tabular}

cilitate reading. Moreover, the facilitation is much greater when the remaining letters of these words are replaced by similar rather than dissimilar letters.

For the similar-letters conditions, presenting even the first letter of the word to the right of fixation resulted in a significant increase in reading rate $[\mathrm{t}(9)=3.68, \mathrm{p}<.005]$ relative to the $0 \mathrm{~W}$ condition, and there was, of course, facilitation when more letters were presented (all ps $<.004$ ). Since the whole next word was never presented in the $0 W+1 L$, $0 \mathrm{~W}+2 \mathrm{~L}$, and $0 \mathrm{~W}+3 \mathrm{~L}$ conditions, this clearly demonstrates that information about the beginning letters of words in parafoveal vision influences reading. Reading rate tended to be higher in the $0 W+3 \mathrm{~L}$ condition than in the $0 \mathrm{~W}+1 \mathrm{~L}[\mathrm{t}(9)=2.48, \mathrm{p}=.035]$ and $0 \mathrm{~W}+2 \mathrm{~L}[\mathrm{t}(9)=2.56, \mathrm{p}=.030]$ conditions. In addition, reading was faster in the $1 \mathrm{~W}$ condition than in the $0 W+1 L(p<.001), 0 W+2 L(p<.001)$, and $0 W+3 L(p=.015)$ conditions. Presenting the whole next word, then, seems to facilitate reading significantly more than presenting only the first few letters of the word. However, much of this effect may have come from words having fewer than four letters, for which three additional letters would not have been presented in the $0 \mathrm{~W}+3 \mathrm{~L}$ condition. It therefore is not clear to what extent letter information beyond the first two or three letters of parafoveal words influences reading.

While presenting an additional whole word to the right of the fixated word increased reading rate as much in the dissimilar-letters condition as in the similar-letters condition, presenting less than the whole word had much smaller effects for dissimilar letters. Reading rate in the $1 \mathrm{~W}$ condition was significantly greater than in any of the other window conditions (all ps $<.001$ ) for dissimilar letters, and there was some tendency for reading to be faster in the $0 \mathrm{~W}+3 \mathrm{~L}$ condition than the $0 \mathrm{~W}, 0 \mathrm{~W}+1 \mathrm{~L}$, and $0 \mathrm{~W}+2 \mathrm{~L}$ conditions $\mathrm{ps}=.045, .023$, and .143 , respectively, by $t$ tests; but all three effects were significant by Newman-Keuls).

Other dependent variables. The significant improvement in reading rate that resulted when addi- tional letters were made available to the right of the word currently fixated did not show up as large effects in any other single dependent variable displayed in Table 3. Rather, changes in reading rate seemed to be associated with relatively small changes in several indices of eye movement.

As was the case for reading rate, analyses of variance revealed significant main effects for parafoveal text pattern and window size. These factors did not interact for the other dependent variables.

With both similar and dissimilar letters, fixation durations were shorter in the $1 \mathrm{~W}$ condition than in the other window conditions (all comparisons were significant, using Newman-Keuls tests). There was also a tendency with similar letters for fixation durations to be shorter in the $0 \mathrm{~W}+1 \mathrm{~L}$ and $0 \mathrm{~W}+2 \mathrm{~L}$ conditions than in the $0 \mathrm{~W}$ condition $(\mathrm{ps}=.022$ and .024 , respectively).

There were no significant pairwise comparisons for saccade length with similar letters, although, with dissimilar letters, saccade length was longer in the $1 \mathrm{~W}$ condition than in the $0 \mathrm{~W}(\mathrm{p}=.002), 0 \mathrm{~W}+1 \mathrm{~L}$ $(p=.002), 0 W+2 L(p=.029)$, and $0 W+3 L(p=.012)$ conditions.

Finally, since the pattern of results was similar for total number of fixations and for number of forward fixations, only the former measure will be discussed. With similar letters, there were more fixations in the $\mathrm{OW}$ condition than in the $\mathrm{OW}+1 \mathrm{~L}$ $(p=.023), 0 W+2 L \quad(p=.004), 0 W+3 L \quad(p<.001)$, and $1 \mathrm{~W}(\mathrm{p}<.001)$ conditions. In addition, there were fewer fixations in the $1 \mathrm{~W}$ condition than in the $0 \mathrm{~W}+1 \mathrm{~L}(\mathrm{p}=.005)$ and $0 \mathrm{~W}+2 \mathrm{~L}(\mathrm{p}=.018)$ conditions. With dissimilar letters, there were fewer fixations in the $1 \mathrm{~W}$ condition than in any of the other window conditions (all ps $<.005$ ) and there tended to be fewer fixations in the $0 \mathrm{~W}+3 \mathrm{~L}$ condition than in the $0 \mathrm{~W}+1 \mathrm{~L}$ condition $(\mathrm{p}=.028)$.

\section{EXPERIMENT 4}

The results of Experiment 3 were consistent with the hypothesis that readers obtain partial informa- 
tion from the beginning letters of words to the right of fixation. However, there was a 37-wpm difference in reading rate between the $0 \mathrm{~W}+3 \mathrm{~L}$ condition and the $1 \mathrm{~W}$ condition (averaged over the similar and dissimilar conditions). Subjects in the experiment reported that, when there were short words to the right of fixation, they often noticed that the last letters were replaced by other letters. This resulted from our practice of uniformly reducing the number of correct letters in the word to the right of fixation if that word had fewer than four letters. Hence, it is not clear whether the difference between the $1 \mathrm{~W}$ and $\mathrm{OW}+3 \mathrm{~L}$ conditions is completely due to perturbing words less than four letters long in the $0 \mathrm{~W}+3 \mathrm{~L}$ condition.

Thus, in Experiment 4, we introduced condition OW $+3 \mathrm{LN}$ ( $\mathrm{N}$ signifies nontruncated), in which the first three letters of the word to the right of the fixated word were visible or the whole word was visible if it had three or fewer letters. In addition, we employed a $0 \mathrm{~W}+3 \mathrm{LT}$ condition ( $\mathrm{T}$ signifies truncated), which was identical to the $0 \mathrm{~W}+3 \mathrm{~L}$ condition in Experiment 3 , and also the $0 \mathrm{~W}$ and $1 \mathrm{~W}$ conditions. As in Experiment 3, both similar letters and dissimilar letters were employed outside the windows.

\section{Method}

There were eight conditions in the experiment, corresponding to a 4 (window size) $\times 2$ (parafoveal text pattern) design. The four window sizes were $0 W, 0 W+3 L T, 0 W+3 L N$, and $1 W$. The parafoveal text patterns were the $S$ and $D$ conditions employed previously in Experiments 2 and 3 . In the $0 \mathrm{~W}$ condition, only the fixated word and words to the left were visible. In the OW+3LT condition, either three letters of the next word or all but one of the letters in the word, whichever was less, were also presented unaltered. In the $0 \mathrm{~W}+3 \mathrm{LN}$ condition, three letters of the next word or all the letters in the word, whichever was less, were presented. In the $1 \mathrm{~W}$ condition, the whole next word was visible. It should be emphasized that, in all conditions, information to the left of fixation was visible and, as in the three previous experiments, all space information was preserved.

Eight subjects participated in the experiment. After reading the eight warm-up sentences, each subject read eight sentences in each of the eight conditions. The sentences were read in the same order by all subjects, but the order of the conditions was counterbalanced across subjects.

\section{Results and Discussion}

Reading rate. Results are displayed in Table 4. An analysis of variance revealed highly significant main effects for window size $[F(3,21)=19.87, p<.001]$ and parafoveal text pattern $[\mathrm{F}(1,7)=43.76, \mathrm{p}<.001]$. As in the other experiments, reading rate was higher when letters outside the window were replaced by letters visually similar to those in the text. It is also quite clear that reading rates were greater when the first three letters of the word to the right of the currently fixated word were presented than when they were not. For similar letters, reading was significantly faster in both the truncated $(0 \mathrm{~W}+3 \mathrm{LT})$ and nontruncated $(0 W+3 L N)$ partial word conditions than in the $0 \mathrm{~W}$ condition $(\mathrm{p}<.002)$. The reading rate was $17 \mathrm{wpm}$ greater in the $1 \mathrm{~W}$ condition than in the $0 \mathrm{~W}+3 \mathrm{LT}$ condition $(\mathrm{p}=.015)$, but only $5 \mathrm{wpm}$ greater in the $1 \mathrm{~W}$ condition than in the $0 \mathrm{~W}+3 \mathrm{LN}$ condition $(p=.610)$. Consequently, there is no evidence from this experiment that with similar letter replacements there was any advantage in displaying, unaltered, more than the first three letters of words in the parafovea.

With dissimilar letters, the data were somewhat more variable, so that while the difference in reading rate between the $\mathrm{OW}$ and $1 \mathrm{~W}$ conditions was as large as it had been with similar letters, it was less significant $[\mathrm{t}(7)=3.39, \mathrm{p}=.012]$. Reading rate was higher in the $1 \mathrm{~W}$ condition than in the $0 \mathrm{~W}+3 \mathrm{LN}$ condition $(p=.004)$ and tended to be higher in the $0 W+3 L N$ condition than in the $0 \mathrm{~W}(\mathrm{p}=.019)$ and $0 W+3 L T(p=.042)$ conditions.

Other dependent variables. Mean fixation duration declined with increasing window size $[F(3,21)=$ $5.70, \mathrm{p}<.01$ ], and fixation durations were shorter with similar than with dissimilar letters $[F(1,7)=$ $24.29, p<.001]$. There was a main effect of window size on saccade length $[F(3,21)=4.37, p<.025]$, but no significant effect due to parafoveal text pattern. No pairwise differences were significant. For total number of fixations, there were main effects of parafoveal text pattern $[F(1,7)=13.62, p<.01]$ and window size $[F(3,21)=18.37, p<.001]$. For dis-

Table 4

Means for the Dependent Variables in Experiment 4

\begin{tabular}{|c|c|c|c|c|c|}
\hline $\begin{array}{l}\text { Window } \\
\text { Condition }\end{array}$ & $\begin{array}{l}\text { Total } \\
\text { Fixations }\end{array}$ & $\begin{array}{l}\text { Forward } \\
\text { Fixations }\end{array}$ & $\begin{array}{c}\text { Forward Fixation } \\
\text { Duration }\end{array}$ & $\begin{array}{c}\text { Forward Saccade } \\
\text { Length }\end{array}$ & $\begin{array}{c}\text { Reading } \\
\text { Rate }\end{array}$ \\
\hline \multicolumn{6}{|c|}{ Similar Letters Conditions } \\
\hline $\begin{array}{l}0 \mathrm{~W} \\
0 \mathrm{~W}+3 \mathrm{LT} \\
0 \mathrm{~W}+3 \mathrm{LN} \\
1 \mathrm{~W}\end{array}$ & $\begin{array}{l}6.5 \\
5.7 \\
5.4 \\
5.6\end{array}$ & $\begin{array}{l}5.8 \\
5.4 \\
5.1 \\
5.2\end{array}$ & $\begin{array}{l}242 \\
232 \\
241 \\
225\end{array}$ & $\begin{array}{l}6.2 \\
6.4 \\
6.9 \\
6.6\end{array}$ & $\begin{array}{l}238 \\
278 \\
290 \\
295\end{array}$ \\
\hline \multicolumn{6}{|c|}{ Dissimilar Letters Conditions } \\
\hline $\begin{array}{l}0 W \\
0 W+3 L T \\
0 W+3 L N \\
1 W\end{array}$ & $\begin{array}{l}7.1 \\
6.1 \\
5.9 \\
6.0\end{array}$ & $\begin{array}{l}6.3 \\
5.7 \\
5.4 \\
5.6\end{array}$ & $\begin{array}{l}262 \\
264 \\
246 \\
233\end{array}$ & $\begin{array}{l}6.0 \\
6.2 \\
6.5 \\
6.5\end{array}$ & $\begin{array}{l}208 \\
234 \\
256 \\
270\end{array}$ \\
\hline
\end{tabular}


similar letters, there tended to be more fixations in the $0 \mathrm{~W}$ condition than in the $1 \mathrm{~W}(\mathrm{p}=.005)$, $0 \mathrm{~W}+3 \mathrm{LN}(\mathrm{p}=.009)$, and $0 \mathrm{~W}+3 \mathrm{LT}(\mathrm{p}=.036)$ conditions. This also was the case (all ps $<.006$ ) for similar letters.

\section{GENERAL DISCUSSION}

\section{Summary of Major Results}

The present experiments focused on exploring more fully the processes of letter and word encoding to the right of fixation during reading. We view the following as major findings: (1) Experiment 1 replicated earlier findings (McConkie \& Rayner, 1975; Rayner, 1975) that had shown that useful letter information was extracted at least nine character positions to the right of fixation, and extended those findings to demonstrate that useful information is extracted from the second word to the right of fixation. (2) However, both Experiments 1 and 2 showed that beyond making more letters visible, preserving all the letters of a word had no special benefit to reading. When performance in conditions in which word integrity was maintained was compared with performance in conditions in which the window was defined in terms of the number of characters visible, the performance in the former could be predicted fairly well by knowing how many letters were visible. On the other hand, performance in conditions in which the window was defined in terms of number of characters visible could not be understood in terms of the number of words completely visible. (3) Experiments 3 and 4 followed up the implication that readers utilize partial letter information from words by explicitly presenting parts of the word to the right of fixation as well as the fixated word. These two experiments both showed that reading was improved by this partial information and that presenting three letters of the word to the right of fixation improved reading almost as much as presenting the entire word. (4) Furthermore, Experiments 2-4 replicated the earlier findings of McConkie and Rayner (1975) that reading was better when letters outside the window were visually similar to the letters of the text they had replaced than when they were dissimilar to the letters that they had replaced. In addition, Experiments 3 and 4 demonstrated that the visually similar letters were particularly helpful when they completed a word for which the first letters were within the window. (5) A surprising result that emerged from a comparison of Experiments 1 and 2 was that when the window to the right was restricted, readers apparently utilized more information from the left of fixation than when the visible area to the right of fixation was unrestricted. This latter finding suggests that the window of attention may be somewhat flexible, depending on the reading conditions. However, from the present experiments, it is not clear whether the greater use of information from the left of fixation when the right window is restricted is due to the restriction of information to the right of fixation per se or is due to the concomitant slowing up of the reading process.

\section{Implications for Language Processing}

The present findings replicate and extend the earlier findings of McConkie and Rayner (1975) and Rayner (1975) that the reader is processing more than a single word on a fixation. This implies that some words are being read (as opposed to being merely "filled in" from contextual cues) while they are not fixated. Furthermore, our finding that partial word information is utilized during reading strongly suggests (see discussion to follow) that an individual word may be processed on more than one fixation.

Both of these findings suggest that any methodology that assumes that the amount of time spent fixating on a word is measuring the time that the word is being processed (e.g., Just \& Carpenter, 1980) will be in error. The error will not be minor: restricting the window to the word fixated reduces reading speed to about $60 \%$ of the normal rate, implying that significantly more information than the fixated word is extracted on many fixations. However, since the area from which information is extracted is relatively small, a careful analysis of eye-movement patterns can reveal interesting things about on-line processing in reading (e.g., Ehrlich \& Rayner, 1981; Frazier \& Rayner, 1982; Holmes \& O'Regan, 1981; Just \& Carpenter, 1980; Rayner, 1977).

\section{Partial Information from Parafoveal \\ Vision Facilitates Reading ${ }^{2}$}

Of primary interest in our experiments is the finding that partially correct information facilitates reading: visually similar letters, which give partially correct information about the letters they replace, facilitate reading (relative to dissimilar letters), as does the correct beginning of the word to the right of fixation. Furthermore, there appears to be an interaction between these two types of partial information, since the facilitative effect of the visually similar letters is most pronounced in conditions in which only the beginning of the word to the right of fixation is correct. Those two findings, together with the finding that reading performance does not suffer appreciably when letters beyond the third letter of the word to the right of fixation are replaced by visually similar letters, suggest that the visual information extracted from the end of the word to the right of fixation either may not be very precise or may not be used very frequently.

These data are consistent with a model in which (1) some internal representation of a word is ac- 
tivated when there exists evidence for the word, (2) feature information from parafoveal vision (or farther away from fixation and hence of lower visual quality) contributes less activation, and (3) identification of the word occurs when the activation achieves some threshold level. According to such a model, partial word information obtained on fixation $\mathbf{n}$ could facilitate reading in two ways. It could contribute activation sufficient to result in identification, or it could merely increase activation (i.e., "prime" the word) so that the threshold is more readily reached when additional information is obtained on fixation $n+1$. Since we have found that the availability of partial word information facilitates reading without resulting in many misidentifications, it seems reasonable to assume that the threshold for identification is set relatively high.

\section{Is Information Integrated Across Fixations?}

A crucial question about the use of partial information is whether the partial information facilitates by "priming" a full identification of a word on a later fixation or whether it leads to full identification (not necessarily veridical) on the fixation that is seen parafoveally. While both the evidence that partial word information facilitates reading and the evidence that preserving word integrity appears to be irrelevant strongly suggest that information on two or more fixations often goes into identifying a word, one cannot disprove the hypothesis that a word is always identified from information extracted on only one fixation (not necessarily when the word is fixated). To focus the issue more sharply, let us try to explain the data assuming that words are completely identified from information extracted on a single fixation.

In such a model, it is clear that one has to postulate that, on a fixation, sometimes one word is identified, sometimes two words are identified, and, possibly, sometimes more than two are identified. How can partial word information be facilitating? According to such a model, given the intraword redundancies of English and syntactic and semantic constraints, partial information is sufficient to produce full (but not necessarily veridical) identification of the word to the right of fixation on a reasonably high proportion of fixations. However, this identification must be veridical enough to produce reasonably low rates of misidentification in normal reading (in which the quality of information in the parafovea is presumably suboptimal) and in conditions with restricted windows in which the information is degraded and yet the frequency of regressions (and presumably misidentifications) is still fairly small. Such a model, in principle, would also explain why visually similar letters outside the window facilitate reading, since these letters would more probably lead to the "correct" identifi- cation of the parafoveal word more frequently than visually dissimilar letters would.

Although such a mechanism may explain part of the facilitation resulting from partial word information (and parafoveal information in general), we feel that it is implausible that it accounts for the whole effect, and, as a result, we feel that the data strongly suggest that many words in reading are processed on more than one fixation. The first problem that we see with the full identification on one fixation model is that it is inconsistent with the data of Experiments 3 and 4 . If enough words were identified fully in the partial word conditions of Experiments 3 and 4 to result in the facilitation that was found, there should also have been a fairly high rate of misidentification of words, especially for short words for which the intraword redundancy is not high. However, the data show that the regression rates in the $0 \mathrm{~W}+3 \mathrm{~L}$ and $1 \mathrm{~W}$ conditions were both low and about equal. Even given the redundancy of English, it is unlikely that facilitation in these conditions was due solely to complete identification of the parafoveal word from the first three letters and some of the features from the remaining letters.

Moreover, it is difficult to see how such an explanation can work for the task (Rayner, McConkie, \& Zola, 1980) in which a parafoveal string is viewed and, when it has been fixated, is changed into a base word that is to be named. In these studies, the (correct) naming of the second word was facilitated when the first string shared the first few letters. Thus, logically, the naming response is produced by integrating information from the two fixations: since it is correct, information from the second fixation must have been extracted, and since partially correct parafoveal information speeds naming times, parafoveal information relevant to the response must have been extracted. Thus, for naming, it is clear that partial information from the parafovea can aid the response to information on a later fixation. One could argue that two completely different mechanisms are operating in the two tasks: parafoveal information impacts on reading solely by full identification of parafoveally presented words, whereas in the naming task, partial information can be utilized. However, it seems rather unparsimonious to assume radically different mechanisms for similar phenomena, especially since the assumption that partial parafoveal information can "prime" later full identification appears to explain both sets of data quite naturally.

A possible further test of the two models is to see where readers fixate when only the initial letters of the parafoveal word are unaltered. If these parafoveal letters are identified, then one might expect subjects to fixate farther to the right in that word than they would if the letters were not identified. On the other hand, if words are always either fully iden- 
tified on a fixation or are not identified at all, then one would not expect the location of fixations within words to be affected by the presence of correct initial (but not final) letters.

The data of Experiments 3 and 4 were analyzed to see whether fixation locations within words differed when partial word information was present and when it was absent. Since the data were quite variable, all the partial information conditions in each experiment were pooled and compared with the $0 \mathrm{~W}$ and $1 \mathrm{~W}$ conditions. In the partial-word conditions of Experiment 3 , the average location of a fixation was 3.20 characters into the word, whereas the average letter position fixated in the $0 \mathrm{~W}$ and $1 \mathrm{~W}$ conditions was 3.17 and 3.19 , respectively. The differences were clearly all nonsignificant (ts $<1$ ). However, in Experiment 4 , the average letter position of fixation in the partial word conditions was 3.10 , as compared with 2.97 for the $0 \mathrm{~W}$ conditions $[\mathrm{t}(7)=1.879, \mathrm{p}=.10]$ and 2.89 for the $1 \mathrm{~W}$ conditions $[\mathrm{t}(7)=3.391, \mathrm{p}<$ .02]. Thus, it appears that, to some extent, partial information does send the eye farther into the words, which lends support to the conclusion that partial information is extracted from the parafoveal word, but that more information needs to be extracted on the next fixation for identification to occur.

To conclude, the data show that partial information is utilized in reading and strongly suggest that words are frequently recognized on the basis of integrating letter information across more than one fixation. These findings suggest that partial parafoveal information can be utilized in a variety of situations. The results of some experiments (McClelland \& O'Regan, 1981; Paap \& Newsome, 1981) have suggested that the facilitation observed in parafoveal naming studies by Rayner and his co-workers (Rayner, 1978; Rayner, McConkie, \& Ehrlich, 1978; Rayner, McConkie, \& Zola, 1980) was limited to situations in which the subject had strong expectations about what the parafoveal word would be. Most troubling was the implication that the priming from parafoveal information might be restricted to (unnatural) situations in which the set of words to be recognized (and named) was quite small. Although the present experiments do not rule out the hypothesis that some sort of expectations about the parafoveal word are needed to make use of partial parafoveal information, they do rule out the notion that a fixed set of 20 or 30 words is needed. Clearly, the expectations in reading are generally fairly weak, since the next word is rarely predictable from the prior context (Gough, Alford, \& Holley-Wilcox, 1981). On the other hand, the prior context may often narrow the set of words so that the constraints in the parafoveal naming experiments and in reading may be fairly similar. Clearly, more research is needed to understand when and how parafoveal information is used in reading.

\section{REFERENCES}

Bouma, H. Visual interference in the parafoveal recognition of initial and final letters of words. Vision Research, 1973, 13, 767-782.

Den Butrman, R., Boersema, T., \& Gerrissen, J. F. Eye movements and the perceptual span in reading. Reading Research Quarterly, 1981, 16, 227-235.

EhrLich, S. F., \& RAYNer, K. Contextual effects on word perception and eye movements during reading. Journal of Verbal Learning and Verbal Behavior, 1981, 20, 641-655.

Frazie R, L., \& RAYNer, K. Making and correcting errors during sentence comprehension: Eye movements in the analysis of structurally ambiguous sentences. Cognitive Psychology, 1982, 14, 178-210.

Gough, P. B., Alford, J. A., \& Holley-Wilcox, P. Words and contexts. In O. J. L. Tzeng \& H. Singer (Eds.), Perception of print: Reading research in experimental psychology. Hillsdale, N.J: Erlbaum, 1981.

Holmes, V. H., \& O'Regan, J. K. Eye fixation patterns during the reading of relative clause sentences. Journal of Verbal Learning and Verbal Behavior, 1981, 20, 417-430.

IKEDA, M., \& SAIDA, S. Span of recognition in reading. Vision Research, 1978, 18, 83-88.

Just, M. A., \& Carpenter, P. A. A theory of reading: From eye fixations to comprehension. Psychological Review, 1980, 87, 329-354.

McClelland, J. L., \& O'Regan, J. K. Expectations increase the benefit derived from parafoveal visual information in reading words aloud. Journal of Experimental Psychology: Human Perception and Performance, 1981, 7, 634-644.

McConkie, G. W., \& RAYNer, K. The span of the effective stimulus during a fixation in reading. Perception \& Psychophysics, 1975, 17, 578-586.

Myers, J. L. Fundamentals of experimental design. Boston: Allyn and Bacon, 1979.

PaAp, K. R., \& Newsome, S. L. Parafoveal information is not sufficient to produce semantic or visual priming. Perception \& Psychophysics, 1981, 29, 457-466.

Pollatse K, A., Bolozky, S., Well, A. D., \& Rayner, K. Asymmetries in the perceptual span for Israeli readers. Brain and Language, 1981, 14, 174-180.

Pollatsek, A., \& RAYNer, K. Eye movement control in reading: The role of word boundaries. Journal of Experimental Psychology: Human Perception and Performance, in press.

RAYNER, $K$. The perceptual span and peripheral cues in reading. Cognitive Psychology, 1975, 7, 65-81.

RAYNER, $K$. Visual attention in reading: Eye movements reflect cognitive processes. Memory \& Cognition, 1977, 5, 443-448.

RAYNER, K. Foveal and parafoveal cues in reading. In J. Requin (Ed.), Attention and performance (Vol, 7). Hillsdale, N.J: Erlbaum, 1978.

RAYNer, K., \& Bertera, J. H. Reading without a fovea. Science, $1979,296,468-469$.

Rayner, K., Inhoff, A. W., Morrison, R. E., Slowiaczek, M. L., \& BERTERA, J. H. Masking of foveal and parafoveal vision during eye fixations in reading. Journal of Experimental Psychology: Human Perception and Performance, 1981, 7, 167-179.

Raynen, K., \& McConkie, G. W. What guides a reader's eye movements? Vision Research, 1976, 16, 829-837.

Rayner, K., McConkie, G. W., \& Ehrlich, S. Eye movements and integrating information across fixations. Journal of Experimental Psychology: Human Perception and Performance, 1978, 4, 529-544.

RAYNer, K., MCConkie, G. W., \& Zola, D. Integrating information across eye movements. Cognitive Psychology, 1980, 12, 206-226.

RAYNer, K., \& SlowiaczeK, M. L. Expectations and parafoveal information in reading: Comments on McClelland and O'Regan. 
Journal of Experimental Psychology: Human Perception and Performance, 1981, 7, 645-651.

Rayner, K., Well, A. D., \& Pollatsek, A. Asymmetry of the effective visual field in reading. Perception \& Psychophysics, $1980,27,537-544$.

\section{NOTES}

1. The limiting factor of our equipment is the time needed to plot the display, which can be as much as $4 \mathrm{msec}$. Within $1 \mathrm{msec}$ after the plotting is completed, the eye position is read and a new display is computed and plotted conditional upon this eye position. The plotting thus goes on independently of whether the eye is judged to be in a saccade or a fixation. The window is defined relative to the letter fixated, so that the window will remain th.. same when a letter is fixated, even if there is a small movement of the eye. A saccade is deemed to have started if two successive eye positions are greater than half a character apart, and a new fixa- tion to have begun when two successive eye positions are within half a character.

2. The results of our experiments can be discussed in terms of either facilitation or interference, depending upon the baseline chosen (cf. Rayner \& Slowiaczek, 1981). However, the implications our data have for the reading process do not depend upon whether the effects are discussed in terms of facilitation or interference. For example, one of our major results was that the reading rate in the $0 \mathrm{~W}+3 \mathrm{~L}$ condition was appreciably higher than in the $0 \mathrm{~W}$ condition. We interpreted this result as indicating that the presence of correct letters at the beginning of the word to the right of the fixated word facilitated reading. We could have said that replacing the letters at the beginning of the word interfered with reading. However, the difference in connotation seems minor and the implications seem the same in both cases.

(Manuscript received October 31, 1981; revision accepted for publication February 16, 1982.) 